\title{
Ácido giberélico auxilia na superação da dormência fisiológica e expressão de vigor das sementes de graviola
}

\author{
Carlos Henrique Queiroz Rego ${ }^{1}$, Fernanda Brito Cardoso ${ }^{1}$, Mayara Fávero Cotrim $^{1}$, Ana \\ Carina da Silva Cândido ${ }^{1}$, Charline Zaratin Alves ${ }^{1}$ \\ ${ }^{1}$ Universidade Federal de Mato Grosso do Sul, Campus de Chapadão do Sul, Chapadão do Sul, Mato Grosso do Sul, Brasil. E-mail:
carlosqueirozagro@gmail.com, fernandabcardoso@hotmail.com, mayaracotrim5@gmail.com, ana.candido@ufms.br,
charline.alves@ufms.br
}

Recebido: 18/12/2017; Aceito: 23/05/2018

\section{RESUMO}

As sementes de graviola (Annona muricata) apresentam tegumento resistente e impermeável, além de substâncias inibidoras que dificultam a germinação das sementes. Assim, objetivou-se avaliar a contribuição da embebição em ácido giberélico para a superação da dormência e aumento da germinação das sementes de graviola. O delineamento experimental foi inteiramente casualizado, com cinco tratamentos e quatro repetições. As sementes foram escarificadas e em seguida embebidas por 24 horas a $25^{\circ} \mathrm{C}$ em soluções contendo $0 ; 50 ; 100 ; 150$ e $200 \mathrm{mg}$ $\mathrm{L}^{-1}(\mathrm{ppm})$ de ácido giberélico. Após este período de embebição as sementes foram submetidas ao teste de germinação, sendo avaliados a porcentagem de germinação, o índice de velocidade e o tempo médio de germinação. As concentrações de ácido giberélico apresentaram efeito sobre a germinação e índice de velocidade de germinação. Conclui-se que a embebição das sementes de graviola na concentração aproximada de 140 ppm de ácido giberélico auxilia na superação da dormência, aumentando a germinação e o índice de velocidade de germinação.

Palavras-chave: Giberelina, Annona muricata, Germinação.

\section{Giberellic acid helps to overcoming of the physological dormency and expression of vigor of the graviola seeds}

\section{ABSTRACT}

The graviola (Annona muricata) seeds present resistant and impermeable tegument, besides germination inhibiting substances that hinder the germination of the seeds. The study aimed at was to evaluate if the imbibition in gibberellic acid contributes to the overcoming of dormancy and the increase of germination of graviola seeds. The experimental design was completely randomized, with five treatments and four replications. The seeds were scarified and then soaked for 24 hours at $25^{\circ} \mathrm{C}$ in solutions containing $0 ; 50 ; 100 ; 150$ and $200 \mathrm{mg} \mathrm{L}^{-1}$ (ppm) gibberellic acid. After this imbibition period the seeds were submitted to the germination test, being evaluated the percentage of germination, the rate of germination and the average time of germination. The concentrations of gibberellic acid had an effect on germination and germination speed index. It can be concluded that the impregnation of soursop seeds at the concentration about of $140 \mathrm{ppm}$ of gibberellic acid helps to overcome dormancy, increasing the germination and the rate of germination.

Key-words: Gibberellin, Annona muricata, Germination 
A graviola (Annona muricata L.) é uma fruta tropical, de relevada importância socioeconômica devido ao aumento da demanda de seu consumo in natura e de seus derivados, tornando-a uma das frutas de maior aceitação comercial no país (Junqueira e Junqueira, 2014). No entanto, a expansão da área plantada está de certa forma limitada devido a problemas de dormência em suas sementes para a produção de mudas.

Na família Annonaceae, a dormência pode ser atribuída à imaturidade do embrião, relação hormonal entre ácido giberélicos (GA) e ácido abscísico (ABA) e também à impermeabilidade do tegumento, água e gases. Lobo et al. (2007) observaram que sementes de A. muricata e $A$. cherimola conseguem absorver água, atribuindo a dormência como morfofisiológica simples, não profunda. A dormência morfológica ocorre devido à imaturidade do embrião e é superada por meio de processos de pós-maturação do embrião; a fisiológica se dá por meio da interação entre inibidores e promotores de germinação, sendo superada por meio da adição de hormônios e fitoreguladores (Cardoso, 2009). A dormência pode ser um obstáculo na produção de mudas, pois as sementes ficam sujeitas a condições adversas, devido à lenta germinação. Além disso, as mudas se tornam desuniformes acarretando grandes perdas (Cardoso, 2004).

Os ácidos giberélicos, como o $\mathrm{GA}_{3}$, são fitormônios que desempenham papel fundamental no processo de pegamento e crescimento dos frutos, bem como no desenvolvimento das sementes (Serrani et al., 2007; Casanova et al., 2009; Jong et al., 2009), além de possuir capacidade de promover a germinação e quebra de dormência de sementes de A. crassiflora, A. squamosa e A. muricata, e também para diferentes cultivares de atemóia (Dalanhol et al., 2013). Silva et al. (2007) verificaram que a aplicação de $173 \mathrm{mg} \mathrm{L}^{-1}$ de ácido giberélico $\left(\mathrm{GA}_{4+7}\right)$ em sementes de $A$. crassiflora promoveu a superação da dormência fisiológica e morfológica, auxiliando no crescimento do eixo embrionário. Segundo Menegazzo et al. (2012), a utilização de ácido giberélico foi o melhor método para superação da dormência em sementes de pinha, todavia, experimentos que definam a melhor concentração desse fitorregulador são necessários.

Assim, objetivou-se avaliar a contribuição da embebição em ácido giberélico para a superação da dormência e expressão de vigor das sementes de graviola. $\mathrm{O}$ experimento foi instalado no Laboratório de Tecnologia de Sementes da Universidade Federal de Mato Grosso do Sul, campus de Chapadão do Sul - MS. As sementes de graviola foram obtidas de frutos adquiridos comercialmente. As sementes foram extraídas manualmente, sendo em seguida lavadas em água corrente para extração da polpa e posteriormente mantidas à sombra em temperatura ambiente por cinco dias.

Todas as sementes foram escarificadas com lixa $\mathrm{n}^{\circ} 60$, no lado oposto ao eixo embrionário, até a exposição de parte do endosperma. Em seguida, foram embebidas por 24 horas a $25{ }^{\circ} \mathrm{C}$ em solução contendo $0 ; 50 ; 100 ; 150$ e $200 \mathrm{mg} \mathrm{L}^{-1}$ (ppm) de ácido giberélico. Após 24 horas de embebição as sementes de graviola se encontram na fase I da embebição; este tempo elevado de embebição (Fase I) é característico da família Annonaceae, conforme relatado por diversos autores. Ferreira et al. (2006) verificaram que as sementes de atemóia apresentaram ponto de mudança entre as fases I e II após 27 horas de embebição e início da fase III após 234 horas. Costa et al. (2011) relataram o período de 60 a 72 horas para o início da fase II da embebição.

Posteriormente foi instalado o teste de germinação, sendo utilizadas quatro repetições de 50 sementes por tratamento, que foram distribuídas em caixas gerbox sobre duas folhas de papel germitest umedecidas com água destilada equivalente a 2,5 vezes a massa do papel seco. As caixas foram mantidas em germinador regulado a 25 ${ }^{\circ} \mathrm{C}$ e as avaliações foram realizadas diariamente computando-se o número de sementes que emitiram a radícula (maior que 2,0 $\mathrm{mm}$ ). Juntamente com o teste de germinação foi calculado o índice de velocidade de germinação por meio da fórmula de Maguire (1962), onde: $\mathrm{IVG}=\mathrm{G} 1 / \mathrm{N} 1+\mathrm{G} 2 / \mathrm{N} 2 \ldots+\mathrm{Gn} / \mathrm{Nn}$; onde: $\mathrm{G} 1, \mathrm{G} 2, \mathrm{Gn}$ = número de plântulas germinadas na primeira, segunda, até a última contagem e $\mathrm{N} 1, \mathrm{~N} 2, \mathrm{Nn}=$ número de semanas desde a primeira, segunda, até a última contagem e o tempo médio de germinação (Labouriau e Valadares, 1976).

$\mathrm{O}$ delineamento experimental foi inteiramente casualizado, com cinco tratamentos e quatro repetições. Os dados foram submetidos à análise da variância e as médias foram comparadas por meio de regressão polinomial a $5 \%$ de probabilidade. As concentrações de ácido giberélico auxiliaram na superação de dormência fisiológica e maior expressão de vigor das sementes de Annona muricata (Tabela 1). Resultados semelhantes foram observados por Ferreira et al. (2002), onde foram avaliadas diferentes concentrações de ácido giberélico na superação de dormência de sementes de A. squamosa L. 
Tabela 1. Germinação (G), índice de velocidade de germinação (IVG) e tempo médio de germinação (TMG) de sementes de graviola (A. muricata) em função de concentrações de ácido giberélico.

\begin{tabular}{cccc}
\hline $\begin{array}{c}\text { Concentrações de } \\
\text { ácido giberélico }\end{array}$ & G & IVG & TMG \\
\hline ppm & $\%$ & - & - \\
\hline 0 & 65 & 3,09 & 21,34 \\
50 & 88 & 4,21 & 21,51 \\
100 & 95 & 4,71 & 21,29 \\
150 & 88 & 4,12 & 21,87 \\
200 & 93 & 4,39 & 22,33 \\
\hline F & $5,97^{*}$ & $4,13^{*}$ & $0,32^{\text {ns }}$ \\
\hline CV $(\%)$ & 11,40 & 14,63 & 6,76
\end{tabular}

*Valor de F significativo no nível de 5\% de probabilidade. ${ }^{n}$ não significativo. $\mathrm{CV}=$ coeficiente de variação.

Tanto a germinação quanto o índice de velocidade de germinação se ajustaram ao modelo quadrático da regressão (Figura 1), sendo que na germinação o ajuste correspondeu à concentração de 141,32 ppm de ácido giberélico e para o índice de velocidade de germinação, o ajuste foi de 131,25 ppm de ácido giberélico. Stenzel et al. (2003) trabalhando com superação de dormência de sementes de A. cherimola e A. squamosa, concluíram que o uso do ácido giberélico a 50 e $100 \mathrm{ppm}$ também proporcionou porcentagem de germinação e índice de velocidade de germinação superiores às sementes não tratadas, independente do material genético

Segundo Bewley e Black (1994), o ácido giberélico atua na expressão gênica sinalizando a síntese de diversas enzimas hidrolíticas, tais como $\alpha \mathrm{e}$ $\beta$ amilase (Taiz e Zeiger, 2017). Entretanto sabe-se que sementes em dormência apresentam baixas concentrações de $\alpha$ amilase (Vieira et al., 2008), sendo necessário que sejam sintetizadas novamente durante a fase da germinação. Portanto, para que haja a indução da síntese dessas enzimas é preciso que as giberelinas estejam disponíveis às sementes, na qual atuarão como ativador de fatores de transcrição, levando a expressão gênica das enzimas amilolíticas. Essas enzimas, por sua vez, quando sintetizadas, serão responsáveis por hidrolisar substâncias do tecido de reserva da semente, que posteriormente serão assimiladas, formando aminoácidos, açúcares e demais substâncias destinadas ao eixo embrionário, estimulando o seu crescimento e alongamento, culminando por fim, com a protrusão da radícula.

Além disso, essas enzimas também atuam na modificação da parede celular, facilitando a ruptura do tegumento (Peng e Harberd, 2002), fazendo com que a germinação ocorra de maneira mais uniforme e rápida, promovendo, portanto, além da maior percentagem de germinação, incremento na velocidade deste processo, influenciando de maneira benéfica o vigor das sementes, fato constatado neste experimento. Paralelamente, a escarificação do tegumento facilitou o processo absorção da solução de ácido giberélico, auxiliando no processo e na velocidade da germinação.

$\mathrm{O}$ ácido abscícico (ABA) em sementes inibe a ação dos promotores da germinação, tais como a giberelinas, levando à condição de dormência. Quando relacionamos a dormência aos promotores e inibidores de germinação, qualquer método que aumente a concentração dos promotores ou que impeça a ação de inibidores é capaz de superá-la. (Borghetti e Ferreira, 2004). Dessa forma, a concentração nas quais os promotores devem ser fornecidos às sementes é de extrema importância, de forma que suprimam o efeito dos inibidores, o que de fato explica o porquê das menores e/ou maiores doses não expressarem efeito significativo na superação da dormência, fato constatado neste experimento. A embebição das sementes de graviola na concentração aproximada de $140 \mathrm{ppm}$ de ácido giberélico auxilia na superação da dormência fisiológica e aumenta a germinação e velocidade de germinação.

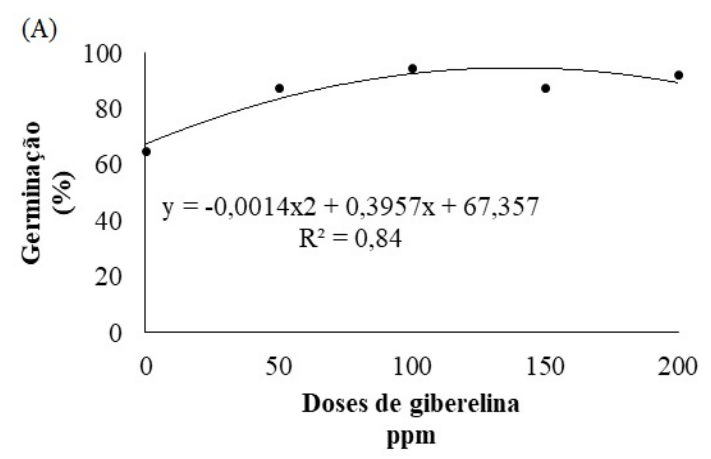

(B)

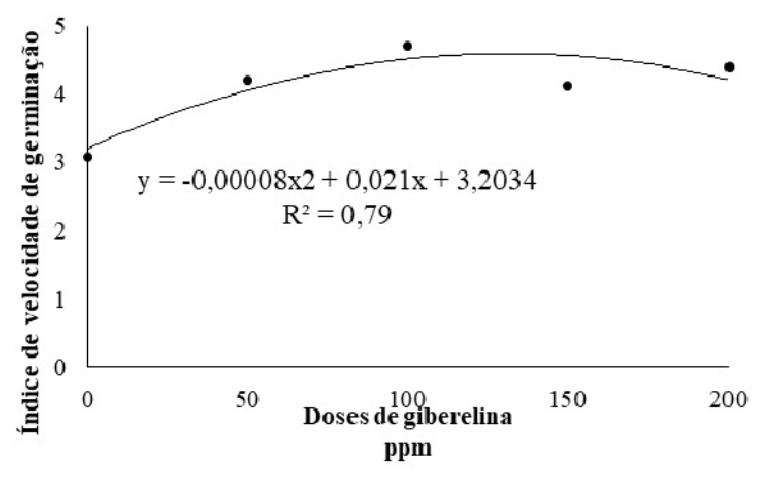

Figura 1. Germinação e índice de velocidade de germinação (IVG) de sementes de graviola (A. muricata) em função de diferentes concentrações de ácido giberélico. 


\section{Referências Bibliográficas}

Bewley, J.D.; Black, M. 1994. Seeds: physiology of development and germination. 2.ed., Plenum Press, New York.

Borghetti, F.; Ferreira, A.G. 2004. Interpretação de resultados de germinação. Germinação: do básico ao aplicado. Artmed, Porto Alegre, pp. 209-222.

Cardoso, V. Germinação. 2004. In: Kerbauy, G.B. Fisiologia Vegetal. Guanabara Koogan, Rio de Janeiro, pp. 386-408.

Cardoso, V.J.M. 2009. Conceito e classificação da dormência em sementes. Oecologia Brasiliensis, 2, 1, 619-631.

Casanova, L.; Casanova, R.; Moret, A.; Agustí, M. 2009. The application of gibberellic acid increases berry size of" Emperatriz" seedless grape. Spanish Journal of Agricultural Research, 7, 4, pp. 919-927.

Costa, P.N.; Bueno, S.S.C.; Ferreira, G. 2011. Fases da germinação de sementes de Annona emarginata (Schltdl.) H. Rainer em diferentes temperaturas. Revista Brasileira de Fruticultura, 33, 1, pp. 253-260.

Silva, E.A.A.; Melo, D.L.; Davide, A.C.; Bode, N.; Abreu, G.B.; Faria, J.M.; Hilhorst, H.W. 2007. Germination Ecophysiology of Annona crassiflora seeds. Annals of Botany, 99, 5, pp. 823-830.

Dalanhol, S.J.; Mombach, T.C.; Toderke, M.L.; Nogueira, A.V.; Bortolini, M.F. 2013. Dormência em sementes de Annona cacans warm.(annonaceae). Revista Acadêmica: Ciência Animal, 11, pp. 183-189.

Jong, M.; Mariani, C.; Vriezen, W.H. 2009. The role of auxin and gibberellin in tomato fruit set. Journal of Experimental Botany, 60, 5, pp. 1523-1532.

Ferreira, G.; Erig, P. R.; Moro, E. 2002. Giberellic acid use on sugar apple (Annona squamosa L.) Seeds aiming seedling production in different packs. Revista Brasileira de Fruticultura, 24, 1, pp. 178-182.

Ferreira, G.; Guimarães, V.F.; Pinho, S.Z.; Oliveira, M.C.; Richart, A.; Braga, J.F.; Dias, G.B. 2006. Curva de absorção de água em sementes de atemoia (Annona cherimola MILL. $\mathrm{x}$ Annona squamosa L.) CV. 'Gefner'. Revista Brasileira de Fruticultura, Jaboticabal, 28, 1, pp. 121-124.
Junqueira, N.; Junqueira, K. 2014. Principais doenças de anonáceas no Brasil: descrição e controle. Revista Brasileira de Fruticultura, 36, 55-64.

Labouriau, L.; Valadares, M. 1976. On the germination of seeds of Calotropis procera (Ait.) Ait. f. Anais. Anais da Academia Brasileira de Ciências, Rio de Janeiro, 48, 2, pp. 263-284.

Lobo, M.; Delgado, O.; Cartagena, J.E.; Fernández, E.; Medina, C.I. 2007. Categorización de la germinación y la latencia en semillas de chirimoya (Annona cherimola L.) Y guanábana (Annona muricata L.), como apoyo a programas de conservación de germoplasma. Agronomía Colombiana, 25, 2, pp. 231-244.

Maguire, J.D. 1962. Speed of germination - aid in selection and evaluation for seedling emergence and vigor1. Crop Science, 2, 2, pp. 176-177.

Marcos Filho, J. 2015. Fisiologia de sementes de plantas cultivadas. 2. ed., Abrates, Londrina.

Menegazzo, M.L.; Oliveira, A.C.; Kulczynski, S.M.; Silva, E.A. 2012. Efeitos de métodos de superação de dormência em sementes de pinha (Annona squamosa L.). Agrarian, 5, 15, pp. 29-35.

Peng, J.; Harberd, N.P. 2002. The role of ga-mediated signalling in the control of seed germination. Current Opinion in Plant Biology, 5, 5, pp. 376-381.

Serrani, J.C.; Sanjuán, R.; Ruiz-Rivero, O.; Fos, M.; GarcíaMartínez, J.L. 2007. Gibberellin regulation of fruit set and growth in tomato. Plant Physiology, 145, 1, pp. 246-257.

Stenzel, N.M.C.; Murata, I.M.; Neves, C. 2003. Superação da dormência em sementes de atemóia e fruta-do-conde. Revista Brasileira de Fruticultura, 25, 2, pp. 305-308.

Taiz, L.; Zeiger, E. 2017. Fisiologia e desenvolvimento vegetal. Artmed editora, Porto Alegre.

Vieira, A.R.; Oliveira, J.A.; Guimaraes, R.M.; Pinho, E.V.R.V.; Pereira, C.E.; Clemente, A.C.S. 2008. Marcador isoenzimático de dormência em sementes de arroz. Revista Brasileira de Sementes, Lavras, 30, 1, pp. 81-89. 